\title{
Changing Vegetation Patterns in Yobe State Nigeria: An Analysis of the Rates of Change, Potential Causes and the Implications for Sustainable Resource Management
}

\author{
Ali I. Naibbi ${ }^{*}$ Brian Baily, Richard G. Healey, Peter Collier \\ Department of Geography, University of Portsmouth, Portsmouth, UK \\ Email: *ali.naibbi@port.ac.uk
}

Received November 21, 2013; revised December 23, 2013; accepted January 15, 2014

Copyright (C) 2014 Ali I. Naibbi et al. This is an open access article distributed under the Creative Commons Attribution License, which permits unrestricted use, distribution, and reproduction in any medium, provided the original work is properly cited. In accordance of the Creative Commons Attribution License all Copyrights (C) 2014 are reserved for SCIRP and the owner of the intellectual property Ali I. Naibbi et al. All Copyright @ 2014 are guarded by law and by SCIRP as a guardian.

\begin{abstract}
The exploitation of natural resources for timber production, fuelwood use and conversion to agricultural land is increasing to such an extent that the sustainable use of many areas of the world is in doubt. This paper examines three decades of freely available Landsat satellite images of the northeastern part of Nigeria using a supervised classification based technique to create maps of vegetation change in Yobe State. The maps are then used to examine the temporal and spatial aspects of changes which have occurred in the context of previous evidence and literature. The results indicate that the vegetation of the area has drastically reduced since the 1970's. However, as this study shows, the pattern of these changes is complicated and cannot be explained by any single physical or anthropogenic causal factor. Similarly, evidence from ground truthing investigation indicates the importance of fuelwood collection to the deforestation process within the region. This article shows the value of an existing remote sensing and image processing methodology for the assessment of vegetation change in developing countries in relation to the sustainable management of natural resources. The study also discusses the overall change within the study area and discusses several potential causative factors of the observed patterns of change.
\end{abstract}

\section{KEYWORDS}

Savanna Vegetation; Yobe State; Fuelwood; Remote Sensing; Land Cover; Deforestation; Sustainable Management

\section{Introduction}

Sustainable natural resource management is imperative if we are to maintain the natural resource base for future generations. Around the world, many natural resources are being depleted faster than it is possible for nature to replenish these (see for example [1,2]). Two aspects of crucial importance in natural resource management are the need for an inventory of an environmental resource and informed knowledge of the spatial and temporal patterns of change to this resource [3]. With regard to large areas of vegetation cover, remote sensing provides an invaluable tool in the management and assessment of natural resources (see for example [3,4]). Various techniques using satellite imagery or aerial imagery have

\footnotetext{
*Corresponding author.
}

been employed to monitor changes in vegetation cover in Africa and around the world. Remote sensing is a particularly valuable tool in the study of vegetation cover change over large areas. Platforms such as the Landsat satellite programme offer freely available, multispectral data which can be analyzed to examine broader vegetation change. Analysis of patterns and rates of change may provide invaluable information for environmental managers and policy makers.

This study concentrates on land cover and vegetation change in northern Nigeria. The northern part of Nigeria, which is endowed with a large expanse of arable land, and a huge potential for crop production is being threatened by both climate change and man-made deforestation, which has over the years proven to be the cause of the major decline in vegetation cover in the region. A very 
popular, though unscientific claim, among researchers and policy makers in Nigeria, is that the country, with a total area of $923,768 \mathrm{~km}^{2}$, is annually losing about 3500 $\mathrm{km}^{2}$ of its arable land to desertification (encroaching southwards from the north), leading to demographic displacements in some villages across 11 states in the north [5]. Yobe state is one of the worst affected areas, and Odiogor ([5]) quoted the Yobe state governor, Alhaji Ibrahim Geidam, emphasising that "sand dunes are encroaching at a rate of $0.3 \mathrm{~km}^{2}$ annually in the northern part of Yobe state; taking over villages". While climatic change is very popular among environmentalists, as being the main cause of vegetation decrease in the northern part of Nigeria, some also believe that the high demand for both agricultural land and fuelwood in the region is a major contributor to the region's vegetation decline $([6,7])$. Even though the consumption of fuelwood is undoubtedly high in the region, the work of some earlier researchers exaggerated the situation. A notable example is the work of Bdliya (in [7]), who reported that the way in which vegetation was being used for fuelwood in some areas of Borno and Yobe states, would lead to the absence of vegetation cover in the area by 2000. This was demonstrably not the case. While Bdliya's claims did not materialise, some recent global vegetation modellings (using Remote Sensing) of Sub-Saharan Africa (SSA) (between 1982 and 1999-see for example [8] and between 1981 and 2003-see for example [9]), have revealed that the vegetation of most areas in the region is increasing (Northern Nigeria included). These two contrasting statements require further localised investigation in order to assess the resilience of the region's vegetation, which is the aim of this paper.

The study of land cover change in developing countries has been prioritised by researchers and policy makers in recent times [10,11]. Land cover studies are essential for the assessment and management of natural resources and the implementation of management approaches and policies. There has been little research in the area of land use and land cover in Nigeria [12] and the majority of the African countries as a whole. This was originally highlighted by the Food and Agricultural Organisation (FAO) in the late 1970's during its forest assessment project [13]. The FAO claimed at that time that there was a lack of sufficient data for the assessment of the state of the forest areas that could assist in the identification or prediction of forest areas under threat or where reserves and shelter belts needed to be located [13]. The vegetation change pattern in Nigeria represents a unique situation, as highlighted in the 2010 forest assessment report [4]. Nigeria recorded the highest percentage of forest loss among the ten top countries with the largest net loss of forest area since 1990 ([4] p. 21). The report further attributed this loss partly to the high demand and consumption of fuelwood in the country. This is an important concern in the northern part of the country where the savanna vegetation prevails [14]. This study primarily looks at mapping land cover change in some parts of Yobe state, northeastern Nigeria (Figure 1). Within this region, the exploitation of the savanna region of Nigeria (see Figure 2) has been declared as unsustainable in terms of meeting its fuelwood demand, on which the majority of its population depend [14]. As a consequence, if vegetation studies in this part of Nigeria are to be implemented, both the past and recent patterns of vegetation change require close monitoring through empirical studies. This approach was earlier supported by Forsyth ([3] p. 33-36) and Adams ([15], pp. 242-243), who argued that localised empirical studies are needed in the study of deforestation. At the same time, it is of critical importance that the underlying local cause(s) and reason(s) for deforestation are fully understood, in particular because of the alleged misuse of the concept among environmental researchers.

In order to achieve sustainable resource management, comprehensive land cover change information for the entire area is required. One potential tool to establish land cover change is the use of remote sensing techniques. For example, part of the possible reasons given for the apparently slower decline of FAO's figure of the total global net change in forest area from 1990 to 2000 (-8.3 million ha per year) ([4], p. 17), was argued by Mather ([16]) as due to more studies using remote sensing techniques, which have been used to construct a more accurate global forest cover map.

This study therefore investigates Yobe state (an area that falls within those examined by Bdliya (in [7]); Anyambaa and Tucker ([9]) and Olsson et al. ([8]) and one of the country's known "hotspots" for vegetation degeneration [5]), using Remote Sensing and fieldwork-based findings. Initially, this study uses remote sensing techniques to measure the vegetation change in Yobe state. It uses Landsat satellite imagery (freely available from the Global Land Cover Facility, University of Maryland) to classify the changes in vegetated areas over time. Erdas Imagine 11 software is employed for the classification and extraction of land cover statistics. Vegetation change in this study refers to any type of woody cover, which includes both close and open forests, plantations and shrubs. Potential causes of the changes are discussed in the final section of this paper.

\section{Study Area}

Figure 1 shows the location of the study area in Yobe state. Like most Northern Nigerian states, Yobe state is primarily an agricultural area with large expanses of savanna vegetation. Several areas in the northern part of the state have experienced desertification, which is mostly connected to both climate change and man-made 


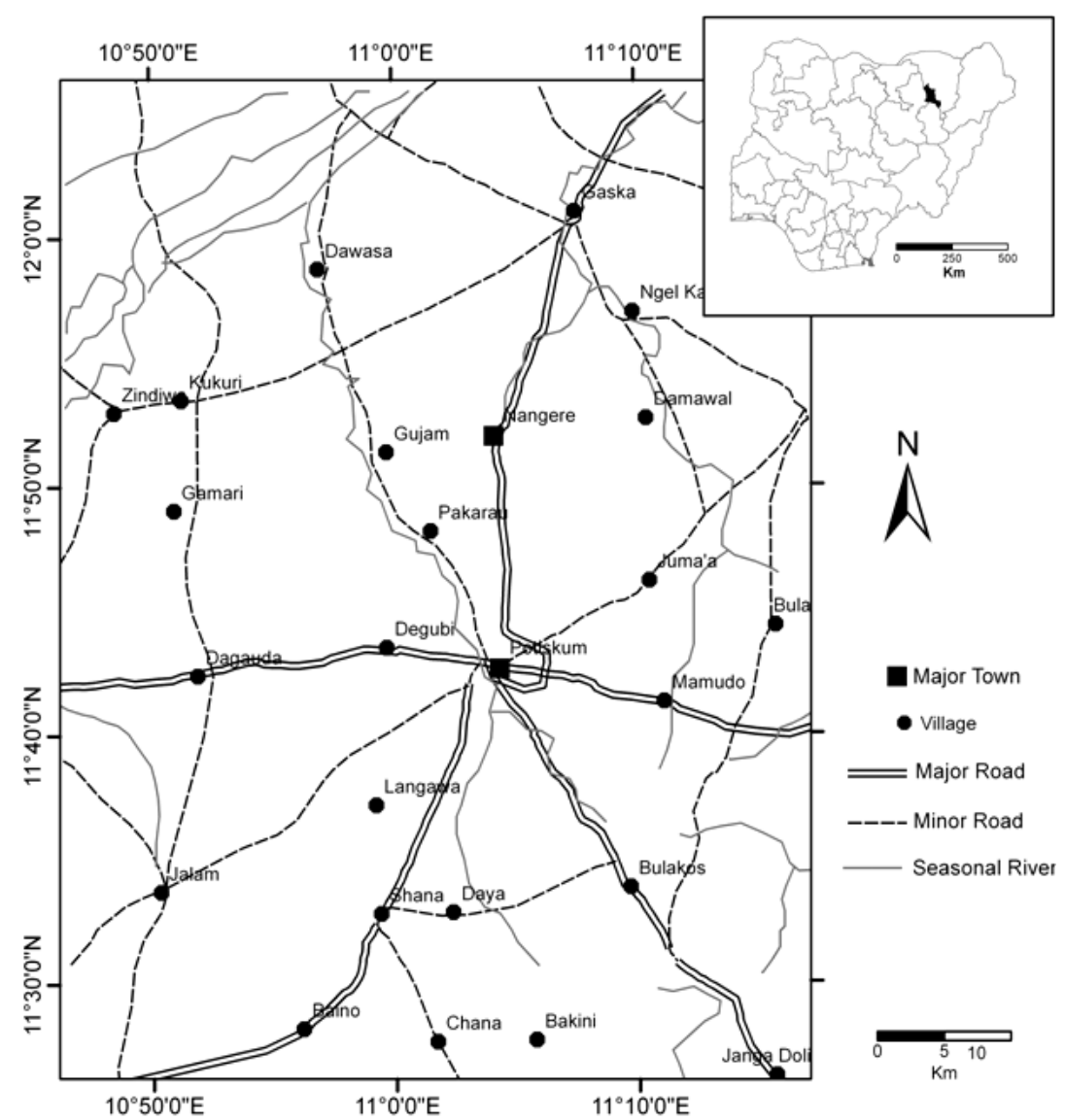

Figure 1. A map showing the location of the study sites of Nangere and Potiskum in north-eastern Nigeria (inset).

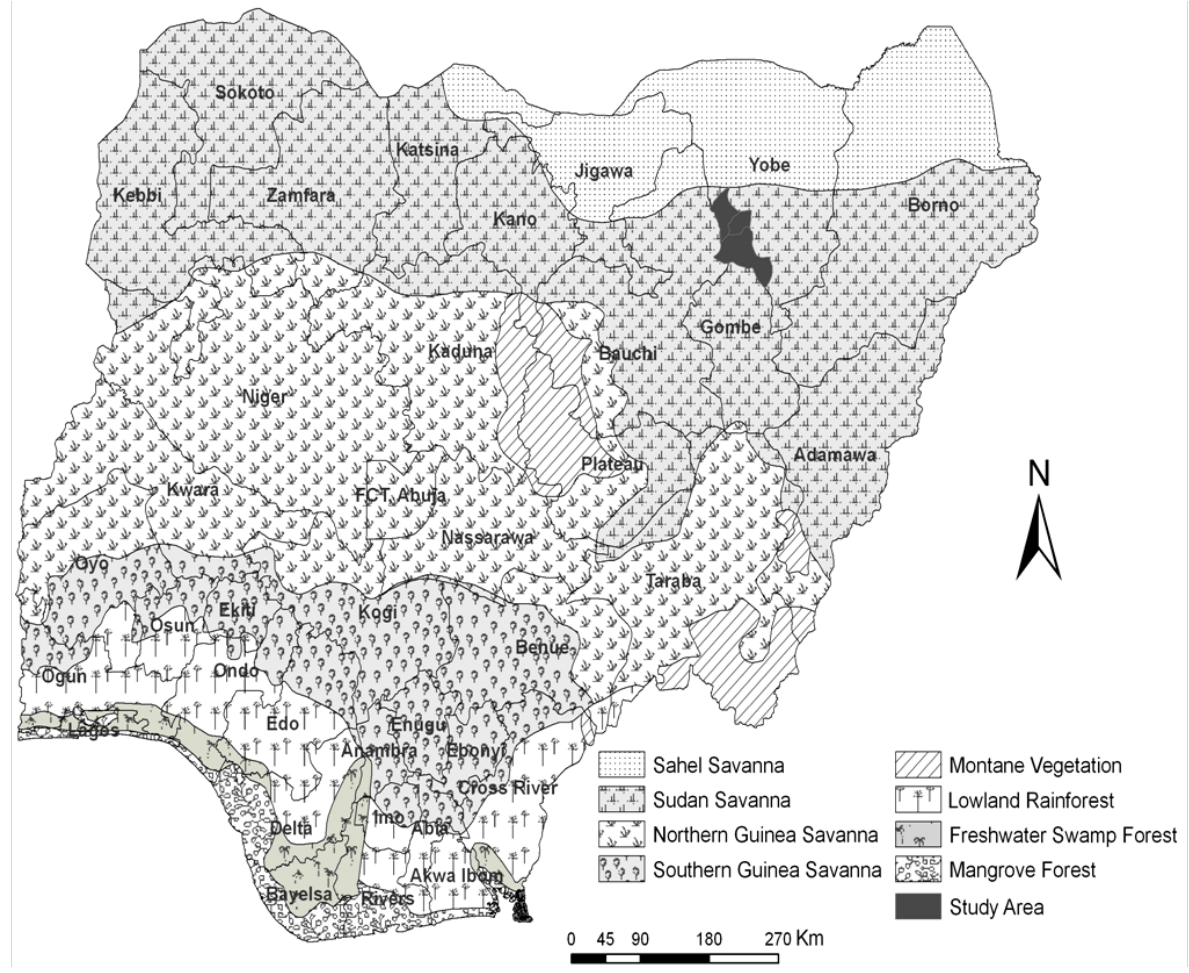

Figure 2. Nigerian ecological zones (Source: map adapted and digitised from FORMECU, (n.d)). 
deforestation ([7]). The southern part of Yobe state including the Potiskum, Nangere and Fika local government areas (referred here to Potiskum and its environs) was selected for investigation here (Latitudes $11^{\circ} 30^{\prime} 33^{\prime \prime} \mathrm{N}$ \& $12^{\circ} 00^{\prime} 00^{\prime \prime} \mathrm{N}$ \& Longitudes $\left.10^{\circ} 50^{\prime} 10^{\prime \prime} \mathrm{E} \& 11^{\circ} 14^{\prime} 11^{\prime \prime} \mathrm{E}\right)$. The choice of these areas was primarily because they have seldom been examined in the previous literature on vegetation degeneration in Yobe state, despite being one of the most densely populated areas in the region. This may be because researchers felt that the area, despite its large population, was less prone to desertification than the northern parts of Yobe state (see Figure 2, Yobe state is covered by two vegetation zones; Sahel Savanna to the north and Sudan Savanna to the south). The study area falls within the Sudan Savannah vegetation zone, and is characterised by a hot and dry climate for most of the year [17]. The dry season starts from early November to late May and the hottest months are March, April and May with temperatures ranging between $39^{\circ} \mathrm{C}$ and $42^{\circ} \mathrm{C}$. The period of the rainy season in the area varies, but generally lasts for about 120 to 140 days from June to early October and ranges between $500 \mathrm{~mm}$ to $1000 \mathrm{~mm}$ in total [17]. The vegetation zone to which the study area belongs extends across about 11 of the 19 northern states (see Figure 2). Thus the findings potentially have implications for northern regions well beyond the study area itself.

The study area covers approximately $3000 \mathrm{~km}^{2}$, with a population of about 300,000 (National Population Commission of Nigeria [18]. The topography of this area is relatively flat and the elevation is approximately between 450 to 480 meters above sea level [17]. The first author has extensive local knowledge of the study area having lived there for many years.

This is very important because the area (at the moment) is a difficult part of the world in which to undertake fieldwork (due to the Boko Haram crisis- see for example ([19]). Therefore, the choice of the study area facilitated the successful execution of the overall research, because of a pre-existing network of local contacts.

\section{Materials and Methods}

In an approach first suggested by Olsson [20], this study uses the Landsat satellite (MSS and ETM+) and evaluates the extent of the changes in the Sudan savanna vegetation cover around Potiskum and its environs, Yobe state Nigeria. It should be noted the concept of deforestation is still under debate [3] with regards to the "usage of the FAO's (which publishes the most widely cited statistics) definition of the term forest, which is based on a commercial definition that includes both natural forests and forestry plantations as long as they satisfy the quantitative criteria of areas with over 10 percent tree cover and no agricultural activity” ([21] p. 1607). Although
Landsat image analysis can detect tree cover as low as $10 \%$ ([22] p. 92), researchers still suggest that remote sensing should be complemented by in-depth studies at the local level to ensure that deforestation for the purpose of other land use (e.g. agricultural land and fuelwood collection) can actually be identified.

For the purpose of this research, a remote sensing methodology was adopted (see for example Sader and Winne ([23]) and field survey information collected for ground truthing purposes. Landsat imagery was used as it has been proven to be very useful in conservation and in natural resource management at the local level (see for example [22-26]).

Landsat images covering the period from 1975 to 2005 were selected from those available based on quality and temporal spacing. In total eight different epochs were selected (Multispectral Scanner (MSS) images for 1975, 1978, 1984, 1986 and 1987; Enhanced Thematic Mapper Plus (ETM+) for 1999, 2002 and 2005). These images were also selected to provide image capture dates which were the same as far as was possible to remove seasonal effects (see Table 1 ).

The images were also visually checked to ensure weather conditions at the time of image capture were not restrictive (i.e. no excessive cloud or atmospheric interference). The main temporal period selected for examination was between November and January when the study area experiences a dry season. The Landsat imagery from 1978 was chosen for the baseline analysis data set (i.e. the base map from which all subsequent change would be measured - see for example [26]). Previous research suggested that the study area had suffered a severe drought in the early 1970's [27] and that this drought period would have affected the vegetation of the area. It is assumed here that the area had recovered sufficiently by 1978 for meaningful analysis. The MSS Landsat images were enhanced geometrically and resampled to 30 metres in order to enable direct comparison with the Landsat ETM+ sensor images (1999 and 2005) which are also of a 30 metre resolution. The 2005 ETM+ image was used for the registration of the other Landsat imagery.

Table 1. Information about the images used.

\begin{tabular}{cccc}
\hline Image Type & Satellite Type & $\begin{array}{c}\text { Acquisition } \\
\text { Date }\end{array}$ & $\begin{array}{c}\text { Resolution } \\
\text { (Meters) }\end{array}$ \\
\hline MSS 1978 & Landsat-2 & $1978-11-18$ & $60 \times 60$ \\
MSS 1984 & Landsat-5 & $1984-11-20$ & $60 \times 60$ \\
MSS 1987 & Landsat-5 & $1987-01-13$ & $60 \times 60$ \\
ETM+ 1999 & Landsat-7 & $1999-12-08$ & $30 \times 30$ \\
ETM+ 2005 & Landsat-7 & $2005-11-03$ & $30 \times 30$ \\
\hline
\end{tabular}




\subsection{RGB-NDVI Classification}

One of the most effective methods for measuring changes in vegetation cover is to carry out a Normalised Difference Vegetation Index (NDVI) classification. The NDVI is a model that makes use of the differential information arising from the distinctive spectral reflectance properties of healthy vegetation in the red $(\mathrm{R})$ and near infra-red (NIR) portion of the electromagnetic (EM) spectrum. The result of the NDVI analysis is a panchromatic, single layer image where the white areas represent dense and healthy vegetation. In contrast, the darker areas in the image represent land cover with little or no vegetation cover. One of the key advantages of NDVI is its tendency to eliminate errors that can affect the spectral properties of vegetation. This is because green vegetation surfaces absorb proportionally more red light and less infrared light than other surfaces. Therefore, as vegetation increases, high NDVI values are obtained. In contrast, as vegetation decreases, lower NDVI values are found [23].

Note that since the study area experiences only two main distinctive seasons in a year (rainy season and dry season), the choice of the dry season images make it possible for the NDVI results to depict visually the distinction between unvegetated areas (including farmland, because it is devoid of crop plants during the dry season following the harvest) and other vegetation types in the study area.

Once the NDVI image had been created, the images from the different epochs were combined to analyse the change in vegetation cover. Sader and Winne ([23]) developed a technique to visualise vegetation change using three dates of NDVI imagery simultaneously by adopting the simple additive colour method. Additive colour theory simply suggests that RGB are the "primary" colours of white light and all the three colours combined together will result in white, while the absence of all the three colours will produce black in an image [28]. Therefore, by stacking the three years of NDVI images together, a new RGB image is produced (RGB-NDVI) where the colours represent vegetation loss, vegetation gain or no change. Using this approach, major changes in the vegetation cover between years appear as the additive colour combination. The final result of all the image processing stages was a coloured (RGB) image where the non-vegetated areas had been excluded and the coloured areas represented changes in vegetation cover over three separate epochs. From these images it was then possible to automatically calculate areas of cover for each colour, thereby creating maps and areas of change statistics for vegetation cover in the study area.

Note that the changes in vegetation cover for Potiskum and its environs were obtained from the original results of the RGB-NDVI images (1978-2005). However, for a better cartographic visualisation of the pattern of vegetation change (due to the numerous tiny pixels observed in the images), a $7 \times 7$ low-pass window median filter was applied to the images in order to reduce their pixel noise.

\subsection{Accuracy Assessment and Image Results Validation}

Campbell ([29]) argued that the evaluation of image accuracy seldom explicitly considers precision, but rather the accuracy should be appropriate for the purpose at hand. Two types of accuracy assessments are used in this study [29]. They are as follows:

1) "Producers Accuracy (PA)" that corresponds to error of omission (exclusion), which is the percentage of a given class that is correctly identified on map.

2) "Users Accuracy (UA)" that corresponds to error of commission (inclusion), which is the probability that a given pixel will appear on the ground as it is classed.

The majority of vegetation map classifications were assessed using topographic maps as the reference map. It is important at this stage to point out that updating such topographical maps to include all vegetation coverage in most developing countries (including Nigeria) is not very reliable and is therefore not useful when assessing accuracy. For example, the first author's personal observation at the time of writing revealed that the most up-to-date map of the study area was produced in 1985 (East View Cartographic-http://www.cartographic.com/hub/index.asp). As twenty seven years have now elapsed, this map cannot be considered to contain information that reflects current realities on ground. This lack of regular update of the topographical maps of Nigeria was also highlighted in a Nigerian local newspaper (Vanguard of 7/2/2012, p. 30), which quoted the Nigerian Surveyor General (Mr. Peter Nwilo) saying "the last time Nigeria was comprehensively mapped was more than 30 years ago". Therefore, the lack of conviction and failure from both commercial and government agencies to regularly update the maps reveals some of the difficulties in obtaining a reliable and up to date topographical map of the study area that can be used reliably as a reference map. For this reason as well as the choice of technique used in this study (RGB-NDVI), the accuracy assessment was achieved using the original images for each year as the reference map. Cohen et al. ([30]); Sader et al. ([24]) and Sader and Legaard ([26]) employed similar methods using the original Landsat TM image as the reference image in their respective classification accuracy assessments.

Using the accuracy assessment tool in the ERDAS Imagine Software, the accuracy of the classified RGBNDVI images was assessed (see Table 2 for results). In addition to using the original Landsat images as the reference maps, the resulting images were further examined using Google images in conjunction with the personal 
Table 2. RGB-NDVI nine classes comparative accuracy assessment results.

\begin{tabular}{ccccc}
\hline \multicolumn{2}{c}{ RGB-NDVI 1978, 1984 and 1987 } & \multicolumn{2}{c}{ RGB-NDVI 1987, 1999 and 2005 } \\
\hline Producer's Accuracy & & Users Accuracy & Producer's Accuracy & User's Accuracy \\
\hline Overall Classification Accuracy & $84.1 \%$ & $71.0 \%$ & $91.5 \%$ & $85.8 \%$ \\
Overall High Vegetation Classification Accuracy & $75.8 \%$ & $71.1 \%$ & $88.3 \%$ & $87.8 \%$ \\
Overall Low Vegetation Classification Accuracy & $94.4 \%$ & $70.8 \%$ & $95.6 \%$ & $83.3 \%$ \\
\hline
\end{tabular}

knowledge of the study area by the first author (see for example [26]). This method obviates the need for using topographic maps due to the possibilities of error and misrepresentation in determining the correct classes.

From Table 2, all the classification accuracy results (the overall classification accuracy, overall high vegetation classification accuracy and overall low vegetation classification accuracy) show similar patterns of agreement with the NDVI image reference points for the change detection maps (1978-1987 \& 1987-2005). The range of the agreement is between $70 \%$ and $95.6 \%$ respectively for both UA and PA. This high range of accuracy results revealed a satisfactory agreement between the sample control points and the RGB-NDVI classified images.

The visual interpretation of the images using the RGBNDVI techniques explained earlier gave a general idea of the changes that have occurred in the forest area over the period of investigation. However, the need for field verification was emphasised by Tole ([22]) for accuracy assessment. Therefore, the accuracy of the interpreted images was also verified by ground truthing of some selected areas on the analysed images in the field. As part of this process, two afforestation sites and three other areas were visited (in October, 2010). In addition, other places visited during the field investigation were locations identified to the first author by the local commercial fuelwood vendors as fuelwood collection centres in the study area. Through this process, an opportunity for discussion with the fuelwood vendors and a direct comparison of their activities in the forest area with the remote sensing image results was also achieved. The methods used in the field included the use of a Global Positioning System device (GPS) for recording locations and a digital camera for taking photographs of the activities in the areas visited.

\section{Results of the Vegetation Cover Analysis}

The overall pattern of vegetation change for each year is illustrated in Figure 3. The results reveal that about $44.4 \%$ of the study area was covered with vegetation in 1978, but this had reduced to about $27.5 \%$ in 2005 . However, although the results clearly show a decline in total vegetation cover over the study period, the vegetation cover of the area witnessed some considerable fluc- tuations (Figure 3). The years of 1984 and 1999 in particular witnessed a reduction in their vegetation cover, to a little over 23\% compared to the years 1978 and 1987. The changing pattern reveals an increase of about $16.8 \%$ in the vegetation cover of the study area from 1984 to 1987 and an increase of about 4.3\% from 1999 to 2005 (Figure 3). However, apart from these two incidences of vegetation cover increase, all other periods witnessed a substantial decline in the vegetation cover. The periods from 1978 to 1984, and 1987 to 1999 witnessed vegetation decline of about $-20.7 \%$ and $-17.3 \%$ respectively (Figure 3). The vegetation increase from 1984 to1987 is quite high compared to an increase of just about $4 \%$ from 1999 to 2005 and the large reduction of vegetation from 1978 to 1984 and 1987 to 1999 . An important finding therefore is the manner in which the vegetation oscillated repeatedly within the period of investigation. Vegetation cover maps that visually elucidate the vegetation change pattern of the study area were also created for each epoch. Figure 4 shows the changes mapped for the periods 1978 and 2005.

The remote sensing analysis clearly shows large changes in vegetation cover across the study area from 1978-2005. In order to statistically test the validity of these changes (vegetation increase and decrease) over the years, an Analysis of Variance (ANOVA) statistical test was applied to the results. The ANOVA tested the following null hypothesis: "there was no significant difference in the observed vegetation change patterns of the study area over the years". The ANOVA result $(F(1,8)$ $=33.64, \mathrm{P}=0.0004$ or $<0.05$ ) rejected the null hypothesis and confirmed that there was a significant difference in the vegetation change patterns observed between 1978 and 2005 in the study area. Whilst the overall change has been significant there has clearly been a complex pattern of change both temporally and spatially across the region. This change is likely to be the result of complex interactions between natural factors and human pressures on the environment.

\section{Discussion of the Potential Causes of the Land Cover Change}

The results of the vegetation change pattern interpreted from the RGB-NDVI images provide an initial impression of the vegetation cover changes that have occurred 


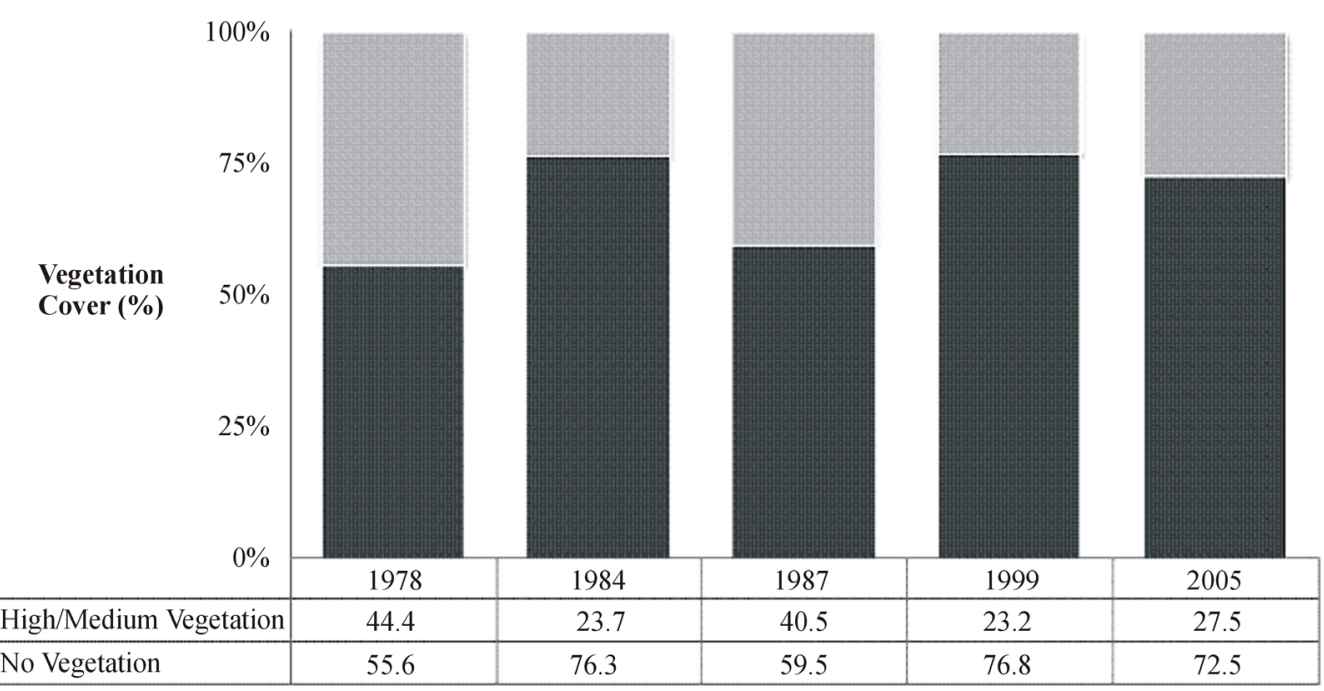

Figure 3. Percentage vegetation cover 1978-2005 (Annual basis).

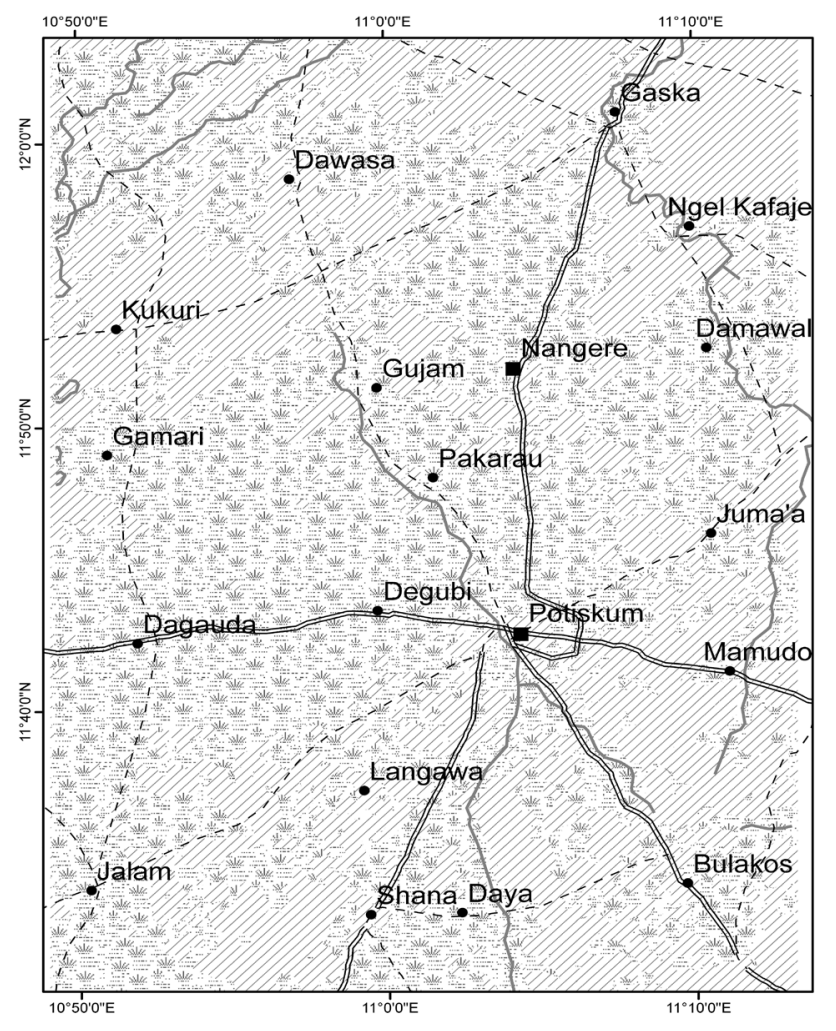

1978 RGB-NDVI Resulting Image
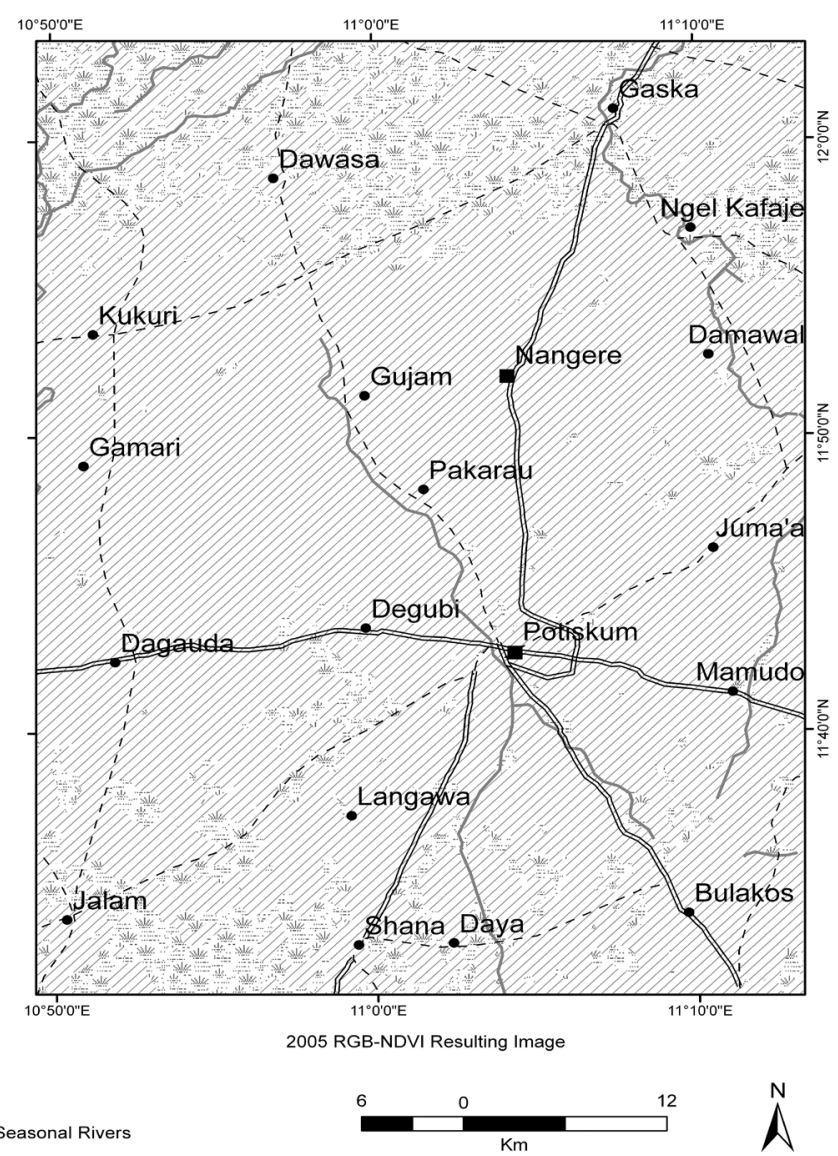

$\stackrel{N}{\Lambda}$

Figure 4. Vegetation cover map of the entire study area for 1978 and 2005.

in the study area over the period of investigation. However, it is worth noting that several factors including physical (rainfall variability), political (local and national government policies) and socio-economic factors (population increase and demand for fuelwood) are believed to be responsible for the observed change patterns. In addition, the influence of some of these factors may vary in temporal and spatial location and variability. As a result, a complex pattern of vegetation increase and decrease occurs across the study area. 


\subsection{Population and Rainfall Factor}

It is suspected that one of the drivers of vegetation change in the region is population increase. Nigeria is yet to fully implement the compulsory registration of births and deaths as legislated since 1979 [31] which means it is difficult to ascertain the exact rate of the country's population increase. There is undoubtedly an upward trend in its population size and the rate of the annual increase was put at 45 per 1000 [32]. This increased rate has resulted in a massive population expansion in Nigeria as a whole and within the current study area. Similarly, demographic change is also a factor at the local scale. For example, Potiskum area has remained the administrative centre of the region's local authority since 1924 [33]. This administrative role has placed the town in a favourable condition to attract more of the nearby population from the surrounding villages and towns (pull factor of population migration [34]). This has resulted in the rapid expansion of the town to cater for the needs of the influx of people. Figure 4 shows a detailed cartographic analysis of the extent to which the vegetation cover around the town of Potiskum has been affected from 1978 to 2005. The population increase can be seen to be partially responsible for the rapid decline of the vegetation as the growing population has increased demand for the construction of social amenities, new housing and the associated increasing demand for farmland to supply the increased population needs. A similar outcome was earlier reported by Odihi ([7]) around the state capitals of Borno (Maiduguri) and Yobe (Damaturu), which all served as the state capitals of the respective study areas. Meeting the increasing population's demand for food was also reported by the Population Reference Bureau (PRB) [34], as a key challenge for the environment through deforestation, particularly in the developing countries (including Nigeria) where the majority of agricultural practice still remains dominated by subsistence farming [34].

One potential physical factor which is likely to have a strong influence on vegetation cover is that of rainfall. Using global modelling of rainfall with NDVI during the rainy season confirmed that rainfall is among the causative factors of vegetation change in the entire region $[8,9]$. However, there was also a reported incidence of consistent reduction in the NDVI of the area during the dry season which cannot be explained by rainfall alone [7]. The vegetation change pattern observed here did not consistently follow the trend of the rainfall pattern observed in Potiskum. The graph of the vegetation changes and rainfall variability in Potiskum reveals that the increased annual rainfall did not necessarily result in increased annual vegetation and similarly decreased annual rainfall did not reflect a decrease in vegetation in the study area (Figure 5). For example, the difference in the amount of the annual rainfall received for the years 1984 and 1987 is low, which contrasts markedly with the massive reduction of vegetation in 1984 compared with the large vegetation increase in 1987. This is despite the fact that 1984 received higher annual rainfall than 1987. Similarly, the years of 1978 and 1987 received rainfall far less than the mean, compared to 1999 which received above the mean and yet witnessed a major vegetation decrease compared with the vegetation increase observed in 1978 and 1987. The contribution of rainfall (quantity received in a particular year) in recharging the underground waters and rivers of northern Nigeria was also considered to have a potential influence on the area's vegetation cover ([17] p. 96, [35] p. 62). This indicates that if there is any direct connection between the rainfall of the study area and the vegetation during the dry season, it could be attributed to the soil moisture content in the periods of drought and excess rainfall ([36], p. 399). For example, the adaptation characteristics of the xerophytic plants during the dry season (the study area's vegetation has some similar characteristics to the neighbouring northern vegetation belt of xerophytic plants which shed their leaves in order to reduce the rate of evapo-transpiration during the dry season) may affect the vegetation health response captured by NDVI, which only records the vegetation index based on high and low leaf cover (chlorophyll). Therefore, the large decrease of vegetation in 1984 (which is bounded by annual rainfall years 1983 and 1985) matches a below mean trend of annual rainfall and the sudden increase of the vegetation in 1987 (which is bounded by annual rainfall years 1986 and 1989 that received more than the mean rainfall) would be logically explained. A statement by the chair of the fuelwood vendors association in Potiskum main market during the field investigation confirmed the reduction of vegetation cover in the study area around 1984 as illustrated in Figures 3 and 5. However, it should be noted that this explanation is purely provisional and therefore remains subject to verification or otherwise in future research. Nevertheless, rainfall variation was not determined in this study to be the principal cause of the vegetation change in the study area.

\subsection{Political Factors: Policies Regarding Afforestation and Agricultural Programmes}

One other potential factor which will undoubtedly have had an effect on the vegetation cover is the local and international effects of the government and government policy. Nigeria has had eight different heads of state from 1978 to 2005, with the majority of these coming to power through military coups. The frequent and sudden changes of government are often accompanied by changing policies and political priorities. For example, the North East Arid Zone Development Programme 


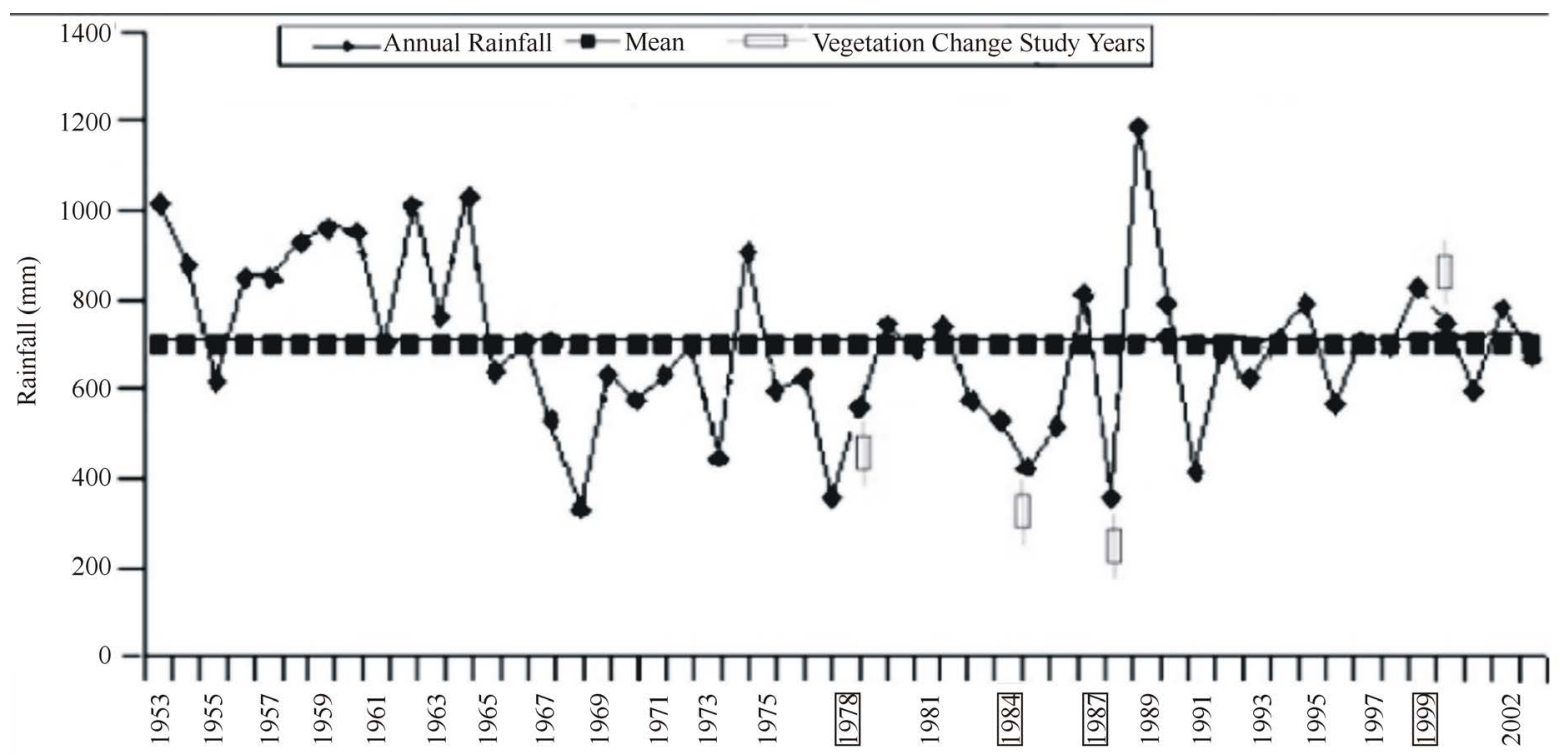

Source: Adopted from Ati et al., (2009 p. 61)

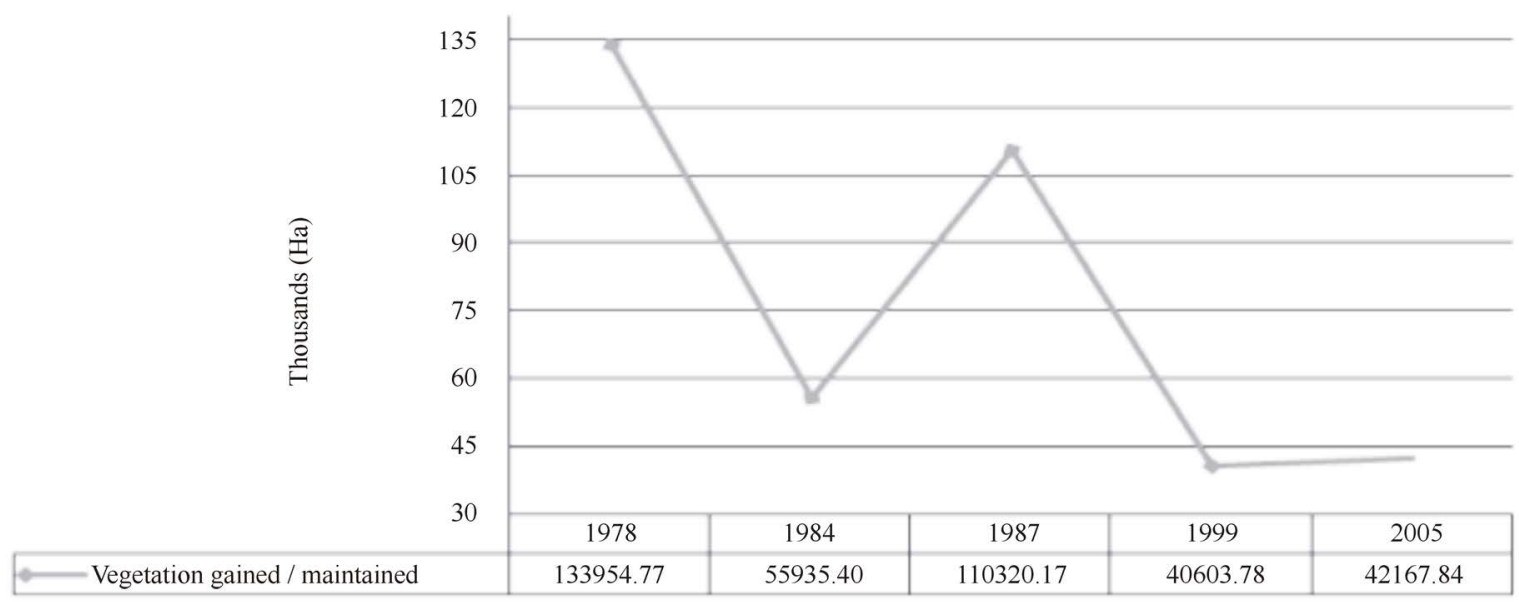

Figure 5. A comparative graph showing the pattern of annual rainfall with vegetation change.

(NEAZDP) had its head office in Yobe State. NEAZDP was a joint rural development programme between the government, people and private enterprise which had the objective of assisting rural populations by improving their living standards through the sustainable use and management of the existing local environmental resources [7]. This scheme only lasted for five years due to political uncertainty (1990-1995). The collapse of the programme was a direct result of the withdrawal of aid by the foreign collaborators when sanctions were imposed on Nigeria during the late General Sani Abacha's regime. The collapse of the NEAZDP resulted in the gradual abandonment of its initial initiatives towards afforestation in the arid zones of Nigeria. Some changes, however, may be directly explained by political factors. For example, the Borno state government's decree during the military regime in 1986. This decree encouraged afforestation and discouraged deforestation by ensuring that trees were not indiscriminately exploited (these laws were contained in the Borno state of Nigeria Gazette [37] under the Borno state Notice No. 62, captioned-“Bos. Edict No. 8 of 1987-The Felling of Trees (Control) Edict, 1986” and Bos. Edict No. 7 of 1987-The Burning of Bush Control (Amendment) Edict, 1987"). Conceivably this might have had some effects on the study area's vegetation cover in the 1990's. Both laws emphasised tough measures against any person caught violating them.

Other policies that may have contributed to the decrease of vegetation in Nigeria may include the government policy of banning the importation of wheat, which is mainly produced in the dry belt regions of Nigeria (including the study area) [7]. This policy paved the way for the clearance of more natural vegetation in order to open up more agricultural land for the production of the commodity. In addition, the establishment of the Directorate 
for Food, Roads and Rural Infrastructure (DFRRI) in 1985 which was circulated under Decree number four of 1987 [38], for the purpose of providing rural infrastructure in the country, was among the Federal Government's policies that may have aided the large reduction in vegetation in the 1990's. For example, the provision of local feeder roads, promoting of rural housing development, provision of rural health care facilities and the boosting of agricultural land all provided by the DFRRI project have directly contributed to the loss of vegetation cover. Other Federal Government policies have also favoured the clearance of more vegetation for agricultural land by the National Agricultural Land Development Authority (NALDA), established under Decree no. 92 [39]. NALDA was specifically initiated by the government in order to help farmers to produce more crops. Although the intention of the Nigerian Government was to help the local population, this research supports the findings of Odihi that both DFRRI and NALDA have contributed significantly to the decrease in vegetation through active deforestation [7]. For example, "during the 8 years of NALDA operation in Nigeria, more than 54,000 hectares of land were acquired within the first year of operation alone (1992 to 1993) of which 28,000 hectares were cleared and utilized. Out of the cleared land, only about 15,000 hectares were cultivated, while the remaining were either left idle or completely abandoned. As of January 2000 when NALDA was scrapped, only a total of 17,820 hectares have been cultivated" ([39] p. 250-251). In Yobe state alone, about 500 hectares of vegetated land were cleared within the first few months of the NALDA project [39].

The government's efforts towards afforestation in the study area are indications that despite establishing policies that encouraged active deforestation, there were countervailing programmes that encouraged forest regeneration. For example, since the 1970s drought that affected the northern part of Nigeria, policies (in the name of the Arid Zone Afforestation Project (AZAP)) were put in place regarding afforestation programmes. Through such programmes, an introduced species of tree called “azadirachta indica” (Neem tree-see example in Figure 6) thrives very well in the study area and has now become one of the most important tree species in terms of use. This is because aside from the main purpose of introducing the Neem tree in the area (environmental protection-to serve as a wind break and sun shade), the local people are becoming more conscious of the tree (through tree ownership) particularly in their compounds (households) and farmlands ([7]). Discussions conducted with the fuelwood vendors during field investigations revealed that unlike the practice in the past when ample vegetation cover existed within short distances from the households, the scarcity of vegetation (espe-
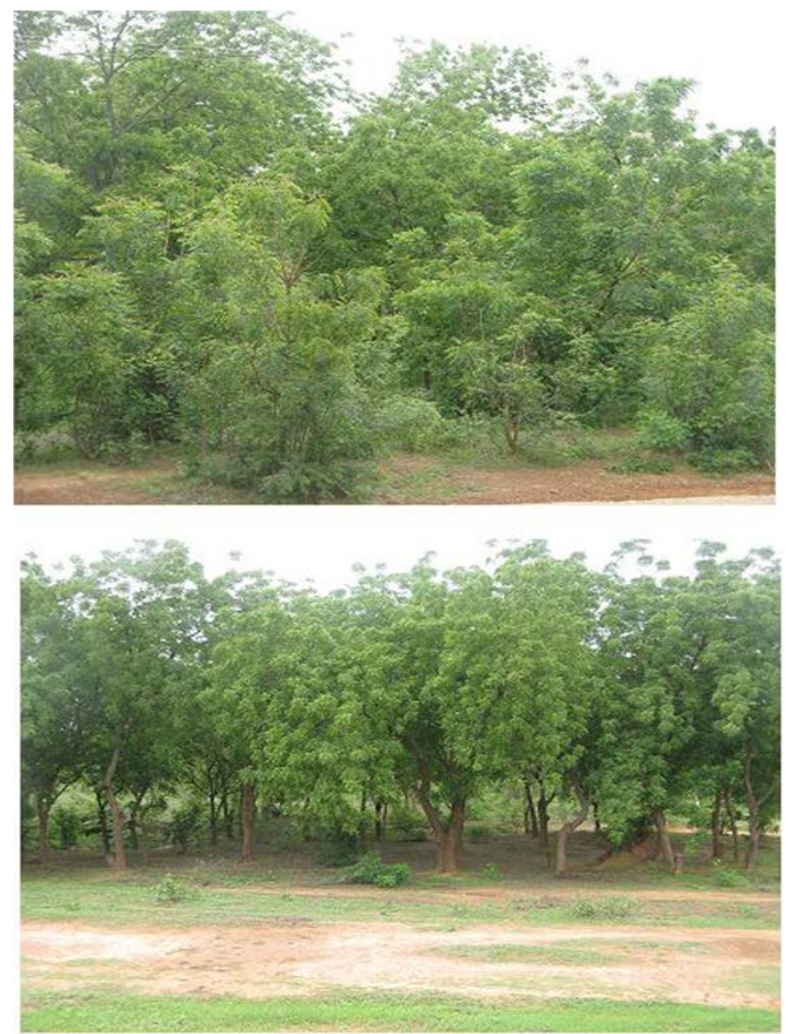

Figure 6. An Example of Neem Trees Afforestation Site (This is close to Potiskum town, Latitude 11.66209, \& Longitude 11.09745 - The trees were planted in the early 1980s) (Source: Photograph by author).

cially for fuelwood) has now necessitated the initiation of changes in perception towards tree ownership as a means of supplementing fuelwood during shortage periods. This change in attitude is especially prominent in Nangere and its surrounding villages (see Figure 4). The shortage of fuelwood in the study area has also resulted in a change of attitude among some farmers, who now also plant Neem trees to supplement other fuelwood sources.

\subsection{Deforestation and Fuelwood Collection}

The complexities of the causes of deforestation that have led to the reduction of vegetation in the study area are varied. The first author's personal experience of the study area has shown that even the vegetation cleared for farmland or settlements were used as fuelwood in the study area. Examples include the new settlements of Sabon Garin Idi Barda and Sabon Garin Bukar Abba, along Potiskum to Damaturu road (Yobe state) which serve as fuelwood purchasing centres for road passengers. Earlier studies of vegetation in northern Nigeria (see for example $[7,40]$ ) also identified the absolute reliance on, and demand for fuelwood as the key factor in deforestation in the northern arid zones of Nigeria. The survey conducted by Max Lock Group Nigeria (MLGN), ([33]), showed 
that there were about six forest reserves within a thirty mile radius of Potiskum town in 1976. The survey warned that these forest reserve areas (a source of fuelwood) were likely to come under pressure in the future due to the dependence on fuelwood and population increase of Potiskum, unless a viable substitute for fuelwood was found. In particular, they emphasised at that time the unsustainable exploitation of unreserved bush areas by fuelwood dealers. During the present field investigation, the chairman of the fuelwood vendors association of Potiskum confirmed that they now have to go beyond their local administrative boundaries in order to procure fuelwood. This is why only two of their present collection centres (Ngel Kafaje and Gada (near Dawasa); northeast and northwest of Nangere respectively-see Figure 4) appeared on the image results. In the areas near these collection centres, the vegetation appears to have drastically declined from 1978 to 2005. At present, about $95 \%$ of the households in Potiskum and its environs are still dependent on fuelwood for their cooking [18].

Mortimore ([41]) also predicted that the growing fuelwood demand in the arid north of Nigeria would continue, because there were no policies in place to discourage the use of fuelwood apart from the existing legislative measures that denied people the use of the only available resources affordable to them. This prediction was confirmed recently (see for example [42,43]) whose recent studies in Kano and Nigeria respectively revealed the current state of deterioration of fossil fuel supplies in the northern part of Nigeria and the over-reliance on fuelwood to meet the cooking energy requirements of the people. It is worth noting that Nigeria has an abundance of crude oil in the South-South region of the country (Niger Delta), which serves as the main source of income of the country. However, the management of the petroleum resources in Nigeria is inefficient and as such, the supply of refined petroleum products to other parts of the country is irregular $([42,43])$. For example, the decrease in fossil fuel supply in the last two decades and the continued shortage of supply due to the various crises in Nigeria has contributed to the decreased amount of vegetation in the study area in the 1990s and 2000s, as a result of increased demand for fuelwood [43]. Figure 7 is an example of one of the numerous fuelwood markets where people purchase fuelwood as part of cooking energy supply options in the study area.

Given the current weak status of the country's infrastructure, economic development and lack of alternative energy sources, the price of fuelwood is far lower than the alternative energy sources of kerosene, gas and electricity, which is why most people depend on fuelwood as their only cooking fuel option [43]. Additionally, with the recent partial withdrawal of fuel subsidy in Nigeria in
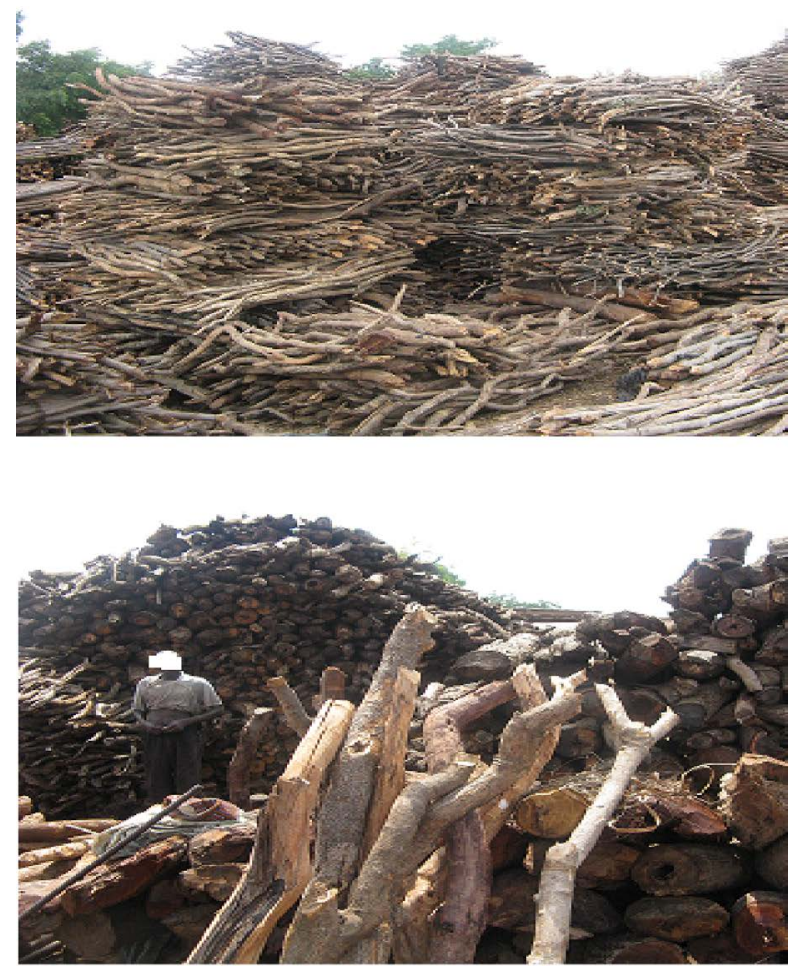

Figure 7. Images of one of the many fuelwood markets in Potiskum (Source: Photograph by author).

January 2012, the prices of fossil fuel soared; this has the implication of committing more people to depend even more on fuelwood. Therefore, in the future if the situation does not change, it is likely that the vegetation in the study area will decline further.

\section{Conclusions}

This investigation sets out to map the pattern of vegetation change in the study area over time using remote sensing to quantify spatial and temporal rates of vegetation loss. It has also endeavoured to suggest some of the potential causes of the observed changes. The interpretation of the RGB-NDVI image results reported here, revealed an irregular pattern of vegetation cover in this part of the Sahel (Potiskum and environs). Periods of remarkable vegetation decrease as well as increase have been identified between 1978 and 2005. The overall pattern is one of vegetation loss, but not as perhaps would have been expected in a clear linear trend. This study has shown an improvement in the vegetation of the study area from 1999 to 2005, which coincided with the regional increase of vegetation as shown by Anyambaa and Tucker ([9] p. 609), Herrmann et al. ([36] p. 398) and Olsson et al. ([8] p. 559). However, it should be noted that the satellite sensors used in the two studies are different and the dates and extent of the two studies differ markedly. 
Understanding the potential causes of these changes appears to be even more complicated than originally expected. A range of possible explanations for the observed patterns of vegetation change have been examined, although it is clear that further research is required to substantiate some of the findings. Many unanswered questions remain, which will help focus future scientific debates on vegetation change in the northern arid zone of Nigeria in general, and the study area in particular. A complex pattern of population increase, national and local government policies and an increasing demand for fuelwood are likely to be the most important factors in explaining the vegetation changes in the study area. In contrast, the direct contribution of rainfall to the explanation of the vegetation change in the study area during the dry season was not found to be substantial, although in reality this would have some effect. From field visits, it is clear that the demand for fuelwood to meet the energy requirements of the people appeared to be a key factor in the vegetation decrease observed over the years.

This study has again demonstrated how low cost remote sensing can be used successfully to study vegetation cover. The RGB-NDVI results also demonstrated empirically the complex nature of the change in vegetation pattern in the study area. Such findings have not been reported in the past for northern Nigeria using the approach adopted here, although the approach has been widely used elsewhere (see for example [23,24]). While the analysis has provided clear evidences of oscillations in vegetation cover in the past, it is not clear whether such oscillations will continue in the future in the same way, because of the progressive loss of forest land due to agriculture, urbanisation and fuelwood collection. However, as future imagery becomes available, the same remote sensing methodology can be used to extend the current analysis for monitoring purpose. The results can then be disseminated to the relevant policy makers for necessary action. This type of information is crucial to the successful sustainable management of natural vegetation cover in many areas around the world.

\section{Acknowledgements}

This research was funded by the Nigerian Petroleum Technology Development Fund (PTDF). All the remote sensing images were freely obtained from the Earth Science Data Interface (ESDI) and US Geological Survey (USGS) (http://glovis.usgs.gov/). We also like to thank the reviewers for their comments and suggestions.

\section{REFERENCES}

[1] K. M. Chomitz and C. Griffiths, "An Economic Analysis and Simulation of Wood Fuel Management in the Sahel," Environmental and Resource Economics, Vol. 19, No. 3,
2001, pp. 285-304. http://dx.doi.org/10.1023/A:1011184808319

[2] G. Perez-Verdin, Y. Kim, D. Hospodarsky and A. Tecle, "Factors Driving Deforestation in Common-Pool Resources in Northern Mexico,” Journal of Environmental Management, Vol. 90, No. 1, 2009, pp. 331-340.

[3] T. Forsyth, "Critical Political Ecology: The Politics of Environmental Science,” Routledge, London, 2003.

[4] Food and Agriculture Organization of the United Nations (FAO), "Global Forest Resource Assessment Main Report 2010,” FAO Forestry Paper, 2011, p. 163. http://foris.fao.org/static/data/fra2010/FRA2010_Report_ en_WEB.pdf

[5] H. Odiogor, "Special Report on Desertification in Nigeria: The Sun Eats Our Land,” Vanguard Newspaper, 2010. http://odili.net/news/source/2010/may/4/300.html

[6] M. J. Mortimore and W. M. Adams, "Farmer Adaptation, Change and Crisis in the Sahel," Global Environmental Change, Vol. 11, No. 1, 2001, pp. 49-57. http://dx.doi.org/10.1016/S0959-3780(00)00044-3

[7] J. Odihi, "Deforestation in Afforestation Priority Zone in Sudano-Sahelian Nigeria,” Applied Geography, Vol. 23, No. 4, 2003, pp. 227-259. http://dx.doi.org/10.1016/j.apgeog.2003.08.004

[8] L. Olsson, L. Eklundh and J. Ardo, "A Recent Greening of the Sahel-Trends, Patterns and Potential Causes," Journal of Arid Environments, Vol. 63, No. 3, 2005, pp. 556566. http://dx.doi.org/10.1016/j.jaridenv.2005.03.008

[9] A. Anyambaa and C. J. Tucker, "Analysis of Sahelian Vegetation Dynamics Using Noaa-AVHRR NDVI Data from 1981-2003,” Journal of Arid Environments, Vol. 63, No. 3, 2005, pp. 596-614.

http://dx.doi.org/10.1016/j.jaridenv.2005.03.007

[10] G. C. Nelson and J. Geoghegan, "Deforestation and Land Use Change: Sparse Data Environments,” Agricultural Economics, Vol. 27, No. 3, 2002, pp. 201-216. http://dx.doi.org/10.1111/j.1574-0862.2002.tb00117.x

[11] P. H. Verburg, K. P. Overmars, M. G. A. Huigen, W. T. De Groot and. A. Veldkamp, "Analysis of the Effects of Land Use Change on Protected Areas in the Philippines," Applied Geography, Vol. 26, No. 2, 2006, pp. 153-173. http://dx.doi.org/10.1016/j.apgeog.2005.11.005

[12] I. A. Ademiluyi. A. S. Okude and C. O. Akanni, "An Appraisal of Land Use and Landcover Mapping in Nigeria," African Journal of Agricultural Research, Vol. 3, No. 9, 2008, pp. 581-586.

[13] D. E. Parry and J. W. Trevett, “Mapping Nigeria’s Vegetation from Radar,” The Geographical Journal, Vol. 145, No. 2, 1979, pp. 265-274. http://dx.doi.org/10.2307/634392

[14] Forestry Management Evaluation and Coordinating Unit (FORMECU), “Nigerian Forestry Action Program,” Federal Ministry of Agriculture and Natural Resources, Abuja, 1996.

[15] W. M. Adams, "Green Development: Environment and Sustainability in a Developing World,” 3rd Edition, Routledge, London, 2009.

[16] A. Mather, "Book Reviews: Global Forest Resources 
Assessment 2000 Main Report FAO Forestry Paper 140, FAO, Rome, 2001,” Land Use Policy, Vol. 20, No. 2, 2003, pp. 195-200. http://dx.doi.org/10.1016/S0264-8377(03)00003-6

[17] T. M. Hess, W. Stephens and U. M. Maryah, "Rainfall Trends in the North East Arid Zone of Nigeria 19611990,” Agricultural and Forest Meteorology, Vol. 74, No. 1-2, 1995, pp. 87-97. http://dx.doi.org/10.1016/0168-1923(94)02179-N

[18] National Population Commission of Nigeria [NPC], "2006 Facts and Figures,” 2010. www.Population.gov.ng/factsandfigures2006

[19] F. Chothia, "Who Are Nigeria's Boko Haram Islamists? BBC African Service," 2012. http://www.bbc.co.uk/news/world-africa-13809501.Acces sed 10/12/2012

[20] K. Olsson, "Fuelwood Demand and Supply in the Umm Ruwaba/Er Rahad Region in N. Kordofan, the Sudan: A Study Based on Field Data and Landsat MSS Information," 2010.

http://www.odi.org.uk/resources/libraries/forestry-grey-lit erature/Olsson.pdf

[21] G. Hiemstra-van der Horst and A. J. Hovorka, "Fuelwood: The 'Other' Renewable Energy Source for Africa?” Biomass and Bioenergy, Vol. 33, No. 11, 2009, pp. 16051616. http://dx.doi.org/10.1016/j.biombioe.2009.08.007

[22] L. Tole, "An Estimation of Forest Cover and Change in Jamaica Using Landsat MSS Data,” International Journal of Remote Sensing, Vol. 23, No. 1, 2002, pp. 91-106. http://dx.doi.org/10.1080/01431160010014837

[23] S. A. Sader and J. C. Winne, "RGB-NDVI Colour Composites for Visualizing Forest Change Dynamics,” International Journal of Remote Sensing, Vol. 13, No. 16, 1992, pp. 3055-3067.

[24] S. A. Sader, M. Bertr and E. H. Wilson, "Satellite Change Detection of Forest Harvest Patterns on an Industrial Forest Landscape,” Forest Science, Vol. 49, No. 3, 2003, pp. 341-353.

[25] P. Leimgruber, C. A. Christen and A. Laborderie, "The Impact of Landsat Satellite Monitoring on Conservation Biology," Environmental Monitoring and Assessment, Vol. 106, No. 1-3, 2005, pp. 81-101. http://dx.doi.org/10.1007/s10661-005-0763-0

[26] S. A. Sader and K. R. Legaard, "Inclusion of Forest Harvest Legacies, Forest Type, and Regeneration Spatial Patterns in Updated Forest Maps: A Comparison of Mapping Results,” Forest Ecology and Management, Vol. 255, No. 11, 2008, pp. 3846-3856. http://dx.doi.org/10.1016/j.foreco.2008.03.047

[27] J. M. Bart, "Pre-Water Audit for the Komadugu-Yobe River Basin, Northern Nigeria and Southern Niger. (IUCN-The World Conservation Union, Federal Ministry of Water Resources and Nigerian Conservation Foundation, Kano, Nigeria),” 2010. http://www.kyb-project.net/_products/200511-pre_water_ audit_KYB.pdf

[28] C. L. Hardin and L. Maffi, "Color Categories in Thought and Language,” Cambridge University Press, Cambridge, 1997. http://dx.doi.org/10.1017/CBO9780511519819
[29] J. B. Campbell, "Introduction to Remote Sensing," 3rd Edition, The Guilford Press, New York, 2002.

[30] W. B. Cohen, M. Fiorella, J. Gray, E. Helmer and K. Anderson, "An Efficient and Accurate Method for Mapping Forest Clearcuts in the Pacific Northwest Using Landsat Imagery," Photogrammetric Engineering and Remote Sensing, Vol. 64, No. 4, 1998, pp. 293-300.

[31] NBS, "Population and Vital Statistics,” 2012. http://www.nigerianstat.gov.ng

[32] NBS, “Social Statistics in Nigeria,” 2012. http://www.nigerianstat.gov.ng

[33] Max Lock Group Nigeria (MLGN), "Potiskum: Surveys and Planning Reports for Borno, Bauchi, and Gongola state Governments between 1973-1976," Warminster Press Ltd., Warminster, 1976.

[34] Population Reference Bureau (PRB), "Human Population: Fundamentals of Growth and Change," Washington DC, 2009.

[35] O. F. Ati, C. J. Stigter, E. O. Iguisi, and J. O. Afolayan, "Profile of Rainfall Change and Variability in the Northern Nigeria, 1953-2002,” Research Journal of Environmental and Earth Sciences, Vol. 1, 2 No., 2009, pp. 5863.

[36] S. A. Herrmann, A. Anyamba and C. J. Tucker, "Recent Trends in Vegetation Dynamics in the African Sahel and Their Relationship to Climate," Global Environmental Change, Vol. 15, No. 4, 2005, pp. 394-404. http://dx.doi.org/10.1016/j.gloenvcha.2005.08.004

[37] Borno State of Nigeria Gazette, "Borno State Notice. No. 62. No. 34 Vol. 12,” Government Printer, Maiduguri, 1987.

[38] L. M. Olayiwola and O. A. Adeleye, "Rural Infrastructural Development in Nigeria: Between 1960 and 1990Problems and Challenges," Journal of Social Sciences, Vol. 11, No. 2, 2005, pp. 91-96.

[39] O. D. Akinsola and O. I. Oladele, "National Agricultural Land Development Authority’s (NALDA) Intervention Programme in Nigerian Agriculture: Lessons and Challenges," Food, Agriculture and Environment, Vol. 2, No. 1, 2004, pp. 249-254.

[40] R. A. Cline-Cole, J. A. Falola, H. A. C. Main, M. J. Mortimore, J. E. Nichol and F. D. O’Reilly, "Wood Fuel in Kano,” United Nations University Press, Tokyo, 1990.

[41] M. J. Mortimore, "Policy Issues,” In: J. Odihi, Deforestation in Afforestation Priority Zone in Sudano-Sahelian Nigeria, Applied Geography, Vol. 23, 1990, pp. 227-259.

[42] R. Maconachie, A. Tanko and M. Zakariya, "Descending the Energy Ladder? Oil Price Shocks and Domestic Fuel Choices in Kano, Nigeria,” Land Use Policy, Vol. 26, No. 4, 2009, pp. 1090-1099. http://dx.doi.org/10.1016/j.landusepol.2009.01.008

[43] A. I. Naibbi and R. G. Healey, "Northern Nigeria’s Dependence on Fuelwood: Insights from Nationwide Cooking Fuel Distribution Data," International Journal of Humanities and Social Science, Vol. 3, No. 17, 2013, pp. 160-173. 